\title{
Strategies for the Prevention and Reduction of Mycotoxins in Developing Countries
}

\author{
Gabriel O. Adegoke and Puleng Letuma \\ Additional information is available at the end of the chapter
}

http://dx.doi.org/10.5772/52542

\section{Introduction}

According to the Fod and Agricultural Organization (FAO) of the United Nations, up to 25\% of the world's food crops have been estimated to be significantly contaminated with mycotoxins (WHO, 1999). Significant losses due to mycotoxins and their impact on human and animal health have been linked with national economic implications and all these factors have combined to make mycotoxins important worldwide (Bhat and Vashanti (1999). According to Plancinta et al. (1999), surveillance studies showed that world-wide contamination of cereal grains and other feeds with Fusarium mycotoxins is a global problem. Thus, in recognition of the global public health importance of food borne diseases and in order to promote economic growth and development, the World Health Organization (WHO) commissioned the Foodborne Disease Burden Epidemiology Reference Group (FERG) to undertake the systematic reviews of some chemicals and toxins like cyanide in cassava, aflatoxin, dioxins and peanut allergens (Hird et al. 2009).

In order to understand the mechanisms that can be adopted for controlling mycotoxins, it is essential to have relevant information on the prevailing climatic conditions in the agricultural zones where the crops are being produced. Thus Bhat and Vasanthi (2003) noted that in developing countries of the world, tropical conditions like high temperatures and moisture, monsoons, unseasonal rains during harvest and flash floods can lead to fungal proliferation and production of mycotoxin. In temperate climates, the most important toxins are deoxynivanelol, (DON), zearalenone, diacetoxyscirpenol (DAS), T-2 toxin and fumonisins (Balazs and Schepers, 2007) and in Europe, the most frequent toxigenic fungi are Aspergillus, Penicillium and Fusarium species (Creppy, 2002).

In cereals grown in temperate regions of America, Europe and Asia, Fusarium spp have been reported to be the most prevalent toxin-producing fungi (Gajecki, 2002). In Africa and other developing countries, the World Health Organization (WHO, 2006) noted that fumonisins 
and aflatoxins are likely to be of significance. However, ochratoxin A (OTA) has been reported in food commodities in Africa, for example, Adegoke et al (2007) found OTA in kunu-zaki (a non-alcoholic beverage); Bonvehi (2004) detected OTA of up to $4 \mathrm{mg} / \mathrm{kg}$-higher than the EU regulatory level- in cocoa powder from Ivory Coast, Guinea, Nigeria and Cameroon. Aroyeun and Adegoke (2007) reported over 50\% occurrence of Aspergillus ochraceus and A.niger in cocoa beans in Nigeria with a corresponding 40-60 ppb OTA concentration.

Consumption of commodities contaminated with mycotoxins according to Bathnagar and Garcia (2001) leads to chronic mycotoxicoses which results in acute poisoning resulting in death. Therefore, as the global occurrence and importance of mycotoxins cannot be overemphasized, methods for preventing and reducing them before entering the food chain must be given continuous attention as $40 \%$ of the productivity lost to diseases in developing countries has been associated with diseases exacerbated by aflatoxins (Miller,1996).

\section{Foodborne mycotoxins}

There are over 300 mycotoxins that have been isolated and characterized (Adegoke, 2004). From the standpoints of health and trade, important mycotoxins are aflatoxins, ochratoxins, deoxynivalenol, zearalenone, fumonisin, T-2 and T-2 like toxins

(trichothecenes) and alternariol. Thomson and Henke (2000) noted that crops in tropical and subtropical areas are more susceptible to mycotoxin contamination than those in temperate zones because the high humidity and temperatures in tropical areas provide optimal conditions for toxin formation. Furthermore, it has been reported that drought conditions can stress plants and render them susceptible to contamination by Aspergillus spp (Holbrook et al. 2004; Robertson, 2005). With respect to some fruits, under warm and humid weather, fruit rots in blueberries are of concern as post-harvest rot can occur on berries that look fine at harvest but carry fungal spores that can infect and develop in the fruits during storage and processing (Schilder et al. 2006). Thus it is important to identify fungal contaminants in fresh fruits because moulds can grow and produce mycotoxins on these commodities (Tournas and Katsoudas, 2005).

\section{Factors that affect mycotoxin production}

In the food chain, there are some 'time-bound' factors that are important in the production of mycotoxins during pre-harvest and post-harvest handling of agricultural products like:

a. intrinsic factors: moisture content, water activity, substrate type, plant type and nutrient composition;

b. extrinsic factors: climate, temperature, oxygen level;

c. processing factors: drying, blending, addition of preservatives, handling of grains

d. implicit factors: insect interactions, fungal strain, microbiological ecosystem (Magan et al. 2004). 


\section{Prevention and reduction of mycotoxins}

Generally, mycotoxin contamination of agricultural products can be prevented using

1. pre-harvest methods:

a. using resistant varieties;

b. field management;

c. use of biological and chemical agents;

d. harvest management and

2. post-harvest methods:

a. improved drying methods;

b. good storage conditions;

c. use of natural and chemical agents

d. irradiation (Kabab et al. 2006).

The inclusion of sorbent materials in feed or addition of enzymes or microorganisms capable of detoxifying mycotoxins have been reported to be reliable methods for mycotoxin prevention in feeds (Jard et al. 2011). However, while bentonite and aluminosilicate clays have been used as binding agents for reducing aflatoxin intoxication in pigs (Schell et al. 1993), cattle (Diaz et al. 1997) and poultry (Scheideler, 1993) without causing digestive problems when mixed with aflatoxin-contaminated feed, care must be taken as the clays can alter nutritional value by binding trace minerals and vitamins and reducing their bioavailability and even produce dioxins (Devegowda and Castaldo, 2000). Preference for esterified glucomannan (a naturally-occurring organic compound in yeast) over clay in reducing the toxicity of aflatoxin has been reported. Devegowda and Castaldo (2000) found that using glucomannan supplementation at $0.05 \%$ of diet of dairy cows that consumed aflatoxin-contaminated feed, there was a reduction of $58 \%$ in aflatoxin in the cow's milk. While in developing countries prevention of mycotoxins from entering the food chain may not currently be receiving sustainable attention or focus as in developed countries because of different food systems, financial constraints, availability of food policies, levels of food safety education and technological development, nonetheless, the following specific mycotoxins can be prevented from developing in agricultural products:

\section{a. Aflatoxins}

Aflatoxins may be produced by three species of Aspergillus-A.flavus, A.parasiticus and the rare A.nomius which according to Creppy (2002) contaminate plants and plant products like peanut, corn, cotton seed and tree nuts (Diener et al. 1987; Horn, 2005). According to Holmes et al. (2008), aflatoxins can be produced (in addition to A.flavus, A.parasiticus and A. nomius) by Aspergillus toxicarius and A. parvisclerotigens on crops like corn, peanuts, cotton seeds and coffee beans. Aflatoxin B 1 according to IARC (1993), is the most carcinogenic, mutagenic and teratogenic substance occurring naturally in foods and feeds. There are reports of the association of aflatoxin contamination of plant foods particularly cereals with liver cancer in Africa and China (Bababunmi, 1978; Oettle, 1964; Li et al. 2001). To prevent aflatoxin contamination of commodities in the farm or during storage of farm products, 
understanding of the prevailing environmental conditions must be considered. Environmental factors that favour Aspergillus flavus infection include high soil or air temperature, drought stress, nitrogen stress, crowding of plants and conditions that aid dispersal of conidia during silking (CAST, 1989; Robens, 1990). The growth of A. flavus and A. parasiticus and subsequent aflatoxin production in storage are favoured by high humidity $(>85 \%)$, high temperature $\left(25^{\circ} \mathrm{C}\right)$ and insect or rodent activity (CAST, 1989). The most important insects that spread A.flavus in postharvest maize are lepidopteran ear borer, Mussidia nigrivenella, Sitophilus zeamais and Carpophilus dimidiatus (Setamou et al. 1998; Hell et al. 2000b). Thus, early harvesting and adequate drying of crops can help in reducing contamination of crops. In several developing countries however, early harvesting, unpredictable weather, labour constraint, need for cash, threat of thieves, rodents and other animals compel farmers to harvest at inappropriate time (Amyot, 1983).

With thorough drying and proper storage of groundnuts in Guinea, Turner et al (2005) reported that there was a $60 \%$ reduction in the mean aflatoxin levels of groundnuts in villages used for the survey. When it is realized that major portion (80\%) of aflatoxin is often associated with small and shrivelled (Davidson et al. 1982) and mouldy and stained peanut (Fandohan et al. 2005; Turner et al. 2005), there are reports of possibility of using physical separation of apparently contaminated cereals from the bulk samples. In Benin, West Africa, Fandohan et al. (2005) used some unit operations like sorting, winnowing, washing, crushing and dehulling to remove significant amounts of aflatoxins and fumonisins in maize and maize products. Park (2002) also noted the effects of processing on aflatoxin.

Employing food safety practices like hazard analysis critical control point (HACCP) system can be useful in preventing and reducing aflatoxin contamination in agricultural products. Hell et al. (2000a) thus noted that cleaning stores before loading new produce correlated with reduced aflatoxin levels. Preharvest HACCP programmes (FAO/IAEA,2001) are available for controlling aflatoxin in corn and coconuts in South east Asia, peanuts, peanut products in Africa, nuts in West Africa, patulin in apple juice and pistachio nuts in South America. While Aldred and Magan (2004) suggested some HACCP approaches for wheatbased commodities, Lopez-Garcia et al. (1999) gave some useful guidance for the development of an integrated mycotoxin management.

Application of potential bio-control agents like atoxigenic strains of Aspergillus flavus and A. parasiticus which when introduced into the soil of growing crops have been reported to produce 74.3 to $99.9 \%$ reduction in aflatoxin in peanuts in the USA (Dorner et al. 1998). The ability of dietary factors to counteract the effects of aflatoxins has been studied. Rompelberg et al. (1996) noted that phenolic compounds can metabolically enhance aflatoxin $B_{1}$ conjugation and elimination. Galvano et al. (2001) also noted that food components like fructose, phenolic compounds, coumarins, chlorophyll and food additives like piperine, aspartame, cyproheptadine and allyl sulfides can reduce the toxicity of mycotoxins by decreasing toxin formation and enhancing metabolism. The antioxidant, ethoxyquin has been reported to be effective as a chemo preventive agent against the carcinogenic effects of aflatoxin $B_{1}$ in humans (Bammler et al. 2000). 
Spices and herbs and their bioactive components have been found useful for the reduction of aflatoxins. Olojede et al. (1993) found that when Garcinia kola was used at $0.32 \%(\mathrm{w} / \mathrm{v})$, aflatoxin was effectively reduced from 97 to $23 \mu \mathrm{g} / \mathrm{ml}$. The bioactive components or volatiles of some plants have been explored in the control of fungal growth and production of aflatoxins, for example, Norton (1999) found that anthocyanins and related flavonoids affect aflatoxin biosynthesis and Juglal et al. (2002) found that spice oil was effective in the control of some mycotoxin producing fungi.

In other studies conducted in a developing country, processing was found to reduce aflatoxins in cereal pastes boiled for 30 and 60 minutes by $68 \%$ and $80.8 \%$ respectively (Adegoke, et al. 1994). During the processing of cassava bread- a cassava-based product, while the initial raw material had aflatoxin level of $1.91 \mu \mathrm{g} / \mathrm{kg}$, however, after processing, the final concentration of aflatoxin in the final product, cassava bread, was found to be $0.03 \mu \mathrm{g} / \mathrm{kg}$ (Adegoke et al. 1993). Roasting of peanuts has been reported to have more effect on reducing chemically detectable aflatoxins than boiling (Njapau et al. 1996). Scott (1991) noted that fermentation of wheat flour dough reduced detectable aflatoxin by approximately $50 \%$ while baking of the dough produced less effect.

Camou-Arriola and Price (1989) found that using $121^{\circ} \mathrm{C}$ and alkaline treatment of naturally contaminated corn prior to frying resulted in very low levels of chemically detectable aflatoxin. Wet, dry milling processes and heat during cooking processes have been found to be effective in reducing levels of aflatoxin in foods (Scott, 1984). Conway et al. (1978); Hale and Wilson (1979) also found significant decreases in aflatoxin content arising from heating and roasting of corn.The use of traditional processing for reducing aflatoxin has also been examined, for example, Hwang et al. (2006) found that processing of traditional Korean foods like 'sujebi' (a soup with wheat flakes) and steamed bread caused $71 \%$ and $43 \%$ decrease respectively in $\mathrm{AFB}_{1}$ levels.

Detoxification using ozone has been found by some workers to be useful in reducing aflatoxins in food commodities for example de Alencar et al. (2012) noted reductions of 30 $\%$ and $25 \%$ for total aflatoxins and aflatoxin $B_{1}$ when peanuts were exposed to $21 \mathrm{mg} \mathrm{L}^{-1}$ of ozone. McKenzie et al. (1997) found that ozone destroyed aflatoxins $B_{1}$ and $\mathrm{G}_{1}$ in aqueous model systems. Prudent and King (2002) reported a $92 \%$ degradation (reduction) in aflatoxin in ozonized contaminated corn. Exposure to sunlight has also been found effective in reducing aflatoxin levels in some food products, for example, Adegoke et al. (1996) found that sun drying of pepper (Capsicum annum) had some significant effects on aflatoxin levels.

\section{b. Ochratoxins}

Benford et al. (2001) noted that Aspergillus ochraceus, A. carbonarius, A. melleus, A.sclerotium and Penicillium verrucosum are the main producers of OTA. Ochratoxins have been detected in several agricultural products from temperate and tropical zones. Weidenborner (2001) found OTA in cassava flour, cereals, fish, peanuts, dried fruits, wine, eggs, milk coffee and cocoa beans. Cereals, wine, grape juice, coffee and pork are the major sources of human 
ochratoxin exposure (JECFA, 2001). Aish et al. (2004) also noted that ochratoxin A (OTA) is found in wheat, corn and oats having fungal infection and in cheese and meat products of animal consuming ochratoxin-contaminated grains.

Post-harvest measures for preventing OTA from entering the food chain have been documented. Magan and Aldred (2007) suggested the following post-harvest critical control points-that can be equally adopted in developing countries:

1. regular and accurate moisture content measurements;

2. efficient and prompt drying of wet cereal grains for safe moisture levels (maize, $14 \%$; rice, $13-14 \%$; barley, $14-14.5 \%$ and canola or rapeseed, $7-8 \%$ );

3. infrastructure for quick response including provision for segregation and appropriate transport conditions;

4. appropriate storage conditions at all stages in terms of moisture and temperature control, general maintenance and effective hygiene of storage facilities for prevention of pests and water ingress.

Modifying the gases in atmospheres where cereals are stored can be used in the prevention of OTA production. Paster et al. (1983), found that OTA production by A.ochraceus was completely inhibited by $30 \% \mathrm{CO}_{2}$. Thus atmospheres greater than $30 \%$ (for example, $30-60 \% \mathrm{CO}_{2}$ ) can be used for preventing OTA production during storage or transportation of grains. This technique can be adopted in developing countries.

Using a combination of cleaning, scouring and removal of the bran and offal fraction, Scudamore et al. (2003) observed an overall reduction of about $75 \%$ of OTA in white bread. Wet- milling, according to Wood (1982), produced $96 \%$ and $49 \%$ reductions of OTA in the germ and grits of corn respectively. The influence of roasting on the reduction of OTA levels has been examined. Van der Stegen et al. (2001) noted that although OTA was relatively stable during heat processing, reductions of OTA of up to $90 \%$ was found during coffee bean roasting. Nehad et al. (2005) found that roasting reduced to $30 \mu \mathrm{g} / \mathrm{kg}$ of OTA by $31 \%$ and filtering reduced OTA by $72 \%$. Using final coffee temperature of $204{ }^{\circ} \mathrm{C}$ (dark roast), Romani et al (2003) obtained reductions of more than $90 \%$ of OTA. Direct removal of damaged coffee has also been found to reduce OTA contamination (CIRAD, http://www.cirad.fr, accessed on 27-03-2012). In Europe, maximum level for OTA in roasted coffee is fixed at $5 \mu \mathrm{g} / \mathrm{kg}$.

In grossly contaminated samples of cocoa beans, the essential oils of some plants can be used to reduce OTA contamination, for example, Aroyeun and Adegoke (2007) used the essential oils of Aframomum danielli to reduce OTA levels in spiked cocoa powder and obtained a reduction efficiency of 64-95\%. Aroyeun et al. (2011) described the potentials of, Aframomum danielli spice in reducing OTA in cocoa powder as the authors found that the powder of $A$. danielli can be used as a biopreservative (maximum concentration of $60,000 \mathrm{ppm}$ ) in cocoa powder contaminated with OTA. Adegoke et al. (2007) reported that during processing, Daniellin ${ }^{\mathrm{TM}}$ completely reduced the OTA level in a non-alcoholic beverage. 


\section{c. Fumonisins}

Fumonisins are produced by Fusarium verticillioides (Sacc.) Nirenberg (=F.moniliforme (Sheldon) and the related F. proliferatum (Matsushima) Nirenberg. Fumonisins occur in sorghum, asparagus, rice, beer and beans (Creppy, 2002). Fumonisins can also be found on asparagus and garlic (Seefelder et al. 2002). In Africa and several other parts of the world, Fusarium spp. are very important field fungi of maize as the fungi produce over 100 secondary metabolites that affect adversely human and animal health (Visconti, 2001). In fact, reports have linked maize consumption with high levels of $F$. verticillioides and fumonisins and high incidence of human oesophageal carcinoma in some parts of South Africa and China (Yoshizawa et al. 1994; IPCS, 2000). Fumonisins are classified as possible human carcinogens (IARC, 1993).

In developing countries and other countries where fumonisins occur in maize, useful preand post-harvest preventive strategies have been suggested by Maga and Aldred (2007):

\section{a. pre-harvest measures:}

1. proper selection of maize hybrids, prevention of use of soft kernel hybrids;

2. no late sowing dates and avoiding high cropping density;

3. good and balanced fertilization;

4. avoiding late harvesting;

5. effective control of pests for example corn borer.

b. post-harvest measures:

1. minimizing periods between harvesting and drying

2. effective cleaning of maize prior to storage;

3. efficient drying to less than $14 \%$ moisture content;

4. effective hygiene and management of silos;

5. absence of pests in store-pests can provide metabolic water and initiate heating. Insect damage of maize is a good prediction of Fusarium mycotoxin contamination which can serve as a warning signal of fumonisin contamination (Avantaggio et al. 2002). Furthermore, the spores of Fusarium spp. can be carried by insects from plant surfaces to the interior of the stalk or kernels or create infection wounds due to the feeding of insect larvae on stalks or kernels (Munkvold and Hellminch. 2000).

6. clear specifications and traceability from field to store.

While these pre-and post-harvest techniques for fumonisin management are not difficult to practise in developing countries, use of solar energy has been found useful elsewhere. Ahmad and Ghaffan (2007) in Pakistan noted that soil solarization was useful in reducing the incidence of corn ear rots and consequently fumonisins and aflatoxins in fields and stored corns. Processing can also be used for reducing fumonisins in food commodities as Jackson et al (1997) noted that when corn-based batter (for making muffins) was baked at $175^{\circ} \mathrm{C}$ and $200{ }^{\circ} \mathrm{C}$ for 20 minutes, reductions of $15 \%$ to $30 \%$ respectively were found with increasing losses as the temperature increased. Voss et al (2001) found a reduction of up to $80 \%$ in fumonisin in fried corn chips - a reduction which was attributed to nixtamilization and rinsing. Combination of agronomic techniques -seed time, seed density, $\mathrm{N}$ fertilization 
and control of corn borer have been reported to be useful in reducing fumonisin contamination in maize (Blandino et al. 2007).

\section{c. Patulin}

Food commodities commonly affected by pathogens that produce patulin are apple, grape, pear, apricots and peaches (Speijers, 2004). The most important aspect of handling patulin is by controlling the quality of fruit before it enters the food chain as patulin is not found in intact fruit because it is the damage done to the surface of the fruit which makes the fruit susceptible to infection by Penicillium spp (Sewram et al. 2000). During the clarification of apple juice and concentrates, Bissessur et al. (2001) found patulin reduction of up to $40 \%$ and using pasteurization or evaporation at $70-100{ }^{\circ} \mathrm{C}$, Kadalal and Nas (2003) found a $25 \%$ loss in naturally contaminated apple juice.

\section{Conclusions}

In reducing mycotoxin accumulation, it must be realized that the concentrations of aflatoxins, deoxynivalenol or fumonisins are greater in symptomatic than in nonsymptomatic maize ears or kernels, thus, prevention or reduction in pre-and post-harvest infection is a critical factor (Scott and Zumno 1995; Reid et al. 1996; Desjardin et al. 1998). While some techniques for the management of mycotoxin contamination may be in practice in developed countries, however, in order to reduce or eliminate rejection of agricultural produce meant for export and at local levels as well as protect consumers from the harmful effects of mycotoxins, developing countries can adopt some of these methods described herein. Harris (1997) also suggested some practical methods for preventing mycotoxin contamination of feeds, for example, keeping grain bins clean and storage at less that $14 \%$ moisture, use of dry feed ingredients that are oxygen-free, fermented or treated with mould growth inhibitors.

For sustained management of mycotoxins along the food chain, the following procedures are recommended:

a. HACCP-compliance: good agronomic practices through transportation and up to consumption;

b. best practices for harvesting, drying and storage of agricultural products coupled with effective insect management;

c. adoption and sustainability of relevant food safety education;

d. careful and systematic enforcement of legislation on food safety.

e. screening in developing countries where fruits and berries are grown and exported for alternariol, alternariol methylether and tenuazonic acid-mycotoxins produced by Alternaria spp (Greco et al. 2012).

f. adoption and utilization of sensitive and reliable methods for detection of mycotoxins. For public health protection and international trade, sensitive and accurate analytical methods are needed for mycotoxins (Rahmani et al. 2009).

g. sustained examination of agricultural commodities under different prevailing climatic conditions. 


\section{Author details}

Gabriel O. Adegoke*

Department of Animal Science, National University of Lesotho, Lesotho

Puleng Letuma

Department of Crop Science, National University of Lesotho, Lesotho

\section{References}

Adegoke, G.O. (2004). Understanding Food Microbiology, Alleluia Ventures Ltd, Ibadan, Nigeria. ISBN 978-36676-1-0 216pp.

Adegoke, G.O; Akinnuoye, O.F.A. and Akanni, A.O. (1993). Effect of processing on the mycoflora and aflatoxin B1 level of a cassava-based product. Plant Foods Hum. Nutrit. 43, 191-196.

Adegoke, G.O; Otumu, F.J. and Akanni, A.O. (1994). Influence of grain quality, heat and processing time on the reduction of aflatoxin $\mathrm{B}_{1}$ levels in tuwo and ogi-two cereal-based products. Plant Foods for Human Nutrition 43, 113-117.

Adegoke, G.O; Allamu, A.E; Akingbala, J.O. and Akanni, A.O. (1996). Influence of sundrying on the chemical composition, aflatoxin content and fungal counts of two pepper varitiesCapsicum annum and Capsicum frutescens. Plant Foods Hum. Nutrit. 49, 113-117.

Adegoke, G.O; Odeyemi, A.O; Hussein, O. and Ikheorah, J. (2007). Control of ochratoxin A in kunu zaki (a non-alcoholic beverage) using Daniellin TM. African Journal of Agricultural Research 2, 200-202.

Ahmad, Y. and Ghaffar, A. (2007). Soil solarization: a management practice for mycotoxins in corn. Pakistan Journal of Botany 39, 2215-2223.

Aish, J.J; Rippon, E.H; Barlow, T. and Hattersley, S.J. (2004). Ochratoxin A. In: Magan, N. and Olsen, S. (Eds), Mycotoxins in Food.: Detection and control, CRC Press, Boca Raton, FL. pp 307-338.

Aldred, D. and Magan, N. (2004). The use of HACCP in the control of mycotoxins: the case of cereals. In: Magan, N, and Olsen, M. (Eds), Mycotoxins in Food: Detection and Control, CRC Press, Boca Raton, FL., pp 139-173.

Alencar, E.R; Faroni, L.R.D; Soares, N.F.F; Silva, W.A. and Carvalho, M.C.S. (2012). Efficacy of ozone as a fungicidal and detoxifying agent of aflatoxins in peanuts. Journal of Science of Food and Agriculture 92, 899-905.

Amyot, J. (1983). Social and economic aspects of dryer use for paddy and other agricultural produce in Thailand. Chualongkorn University Social Research Institute and International Development Research Center, Bangkok, Thailand.

Aroyeun, S.O. and Adegoke, G.O. (2007). Reduction of ochratoxin A (OTA) in spiked cocoa powder and beverage using aqueous extracts and essential oils of Aframomum danielli. African Journal of Biotechnology 6, 612-616.

Aroyeun, S.O; Adegoke, G.O; Varga, J; Teren, J; Karolyi, P; Kuscbe, S. and Valgvolgyi, C, (2011). Potential of Aframomum danielli spice powder in reducing ochratoxin A in cocoa powder. American Journal of Food and Nutrition 1, 155-165.

\footnotetext{
${ }^{*}$ Present address: Faculty of Agriculture, National University of Lesotho, Lesotho
} 
Avantaggio, G; Quaranta, F; Desidero, E. and Visconti, A. (2002). Fumonisin contamination of maize hybrids visibly damaged by Sesamia. Journal of Science of Food and Agriculture 83, 13-18

Bababunmi, E.A; Uwaifo, A.O. and Bassir, O. (1976). Hepatocarcinogens in Nigerian foodstuffs. World Review of Nutrition and Dietetics 28, 188-209.

Balazs, E. and Schepers, J.S. (2007). The mycotoxin threat to food safety. International Journal of Food Microbiology 119,1-2.

Bammler, T.K; Slone, D.H. and Eaton, D.L. (2000). Effects of dietary olipratz and ethoxyquin on aflatoxin B1 biotransformation in non-human primates. Toxicol. Sci. 54, 30-41.

Bathnagar, D. and Garcia, S. (2001). Aspergillus. In: Guide to Foodborne Pathogens, Labbe, R.G. and Garcia, S. (Eds), John Wiley and Sons, New York, pp 35-49.

Bhat, R.V. and Vashanti, S. (1999). Occurrence of aflatoxins and its economic impact on human nutrition and animal feed. The New Regulation Agric. Development No 23, 50-56.

Bhat, R.V. and Vasanthi, S. (2003). Mycotoxin food safety risks in developing countries. Food Safety in Food Security and Food Trade, Vision 2020 for Food, Agriculture and Environment, Focus 10, brief 3 of 17, pp 1-2.

Benford, D; Boyle, C; Dekant, W; Fuchs, E; Gaylor, D.W; Hard, G; McGregory, D.B; Pitt, J.I; Plestina, R; Shephard, G; Solfrizzo, M and Verger, P.J.P. (2001). Ochratoxin A. Safety evaluation of certain mycotoxins in food. WHO, Geneva, WHO Food Additives Series 47, FAO Food and Nutrition Paper vol. 47, pp 281-415.

Blandino, M; Reyneri, A. and Vanara, F. (2007). Strategy for the fumonisin reduction in maize kernel in Italy. Mycotoximes fusariennes des cereals. Areachon, 11-13 sept 2007. www.symposcience.com accessed 09-04-2012.

Bissessur, J., Permaul, K and Odhav, B. (2001). Reduction of patulin during apple juice clarification. Journal of Food Protection 64, 1216-1219.

Bonvehi, J.R. (2004). Occurrence of ochratoxin A in coca products and chocolate. Journal of Agriculture and Food Chemistry 52, 6347-6352.

Camoou-Arriola, J.P. and Price, R. I. (1989). Destruction of aflatoxin and reduction of mutagenicity of naturally-contaminated corn during the production of a corn snack. Journal of Food Protection 52, 814-817.

CAST (1989). Mycotoxins: Economic and Health Risks. United States Council for Agricultural Science and Technology (CAST), Ames, Iowa, Report No 116, pp 1-91.

Conway, H.F; Anderson, R.A. and Bagley, E.B. (1978). Detoxification of aflatoxin contaminated corn by roasting. Cereal Chemistry 55, 115-118.

Creppy, E.E. (2002). Update of survey, regulation and toxic effects of mycotoxins in Europe. Toxicology Letters 127, 19-28.

Davidson, Jr. J.I; Whitaker, T.B. and Dickens, J.W. (1982). Grading, cleaning, storage, shelling, and marketing peanuts in the United States, Patee, H.E; Young, C.T. and Yoakum, T.X. (Eds), American Peanut Research and Education Society, pp 571-623.

de Alencar E.R; Faroni, L.R.R; Soares, N.F.F; Silva, W.A. and Carvalho, M.C.S. (2012). Efficacy of ozone as a fungicidal and detoxifying agent of aflatoxins in peanuts. Journal of Science of Food and Agriculture 92, 899-905.

Desjardin, A.E; Plattner, R.D; Lu, M. and Claflin, L.E. (1998). Distribution of fuminosins in maize ears infected with strains of Fusarium moniliforme that differ in fumonisin production. Plant Diseases 82, 953-958. 
Devegouida, G. and Castaldo, D. (2000). Mycotoxins: hidden killers in pet foods. Is there a solution?. In: Technical Symposium on Mycotoxins, Altech Inc., Nicholasville, KY, USA.

Diaz, D.E; Blackwelder, J.T; Hagler, W.M.Jr; Hopkins, B.A; Jones, F.T; Anderson, K.L. and Whitlow, L.W. (1997). The potential of dietary clay products to reduce aflatoxin transmission to the milk of dairy cows. Journal of Dairy Science 80, 265.

Diener, U.L; Cole, R.J; Sanders, T.H; Payne, G.A; Lee, L.S. and Klich, M.A. (1987). Epidemiology of aflatoxin formation by Aspergillus flavus. Annual Review of Phytopathology 25, 249-270.

Dorner, J.W; Cole, R.J. and and Blakenship, P.D. (1998). Effect of inoculum rate of biological agents on preharvest contamination of peanuts. Biological Control 12,171-176

Fandohan, P; Gnonlonfin, B; Hell, K; Marasas, W.F.O. and Wingfield, M.J. (2005). Natural occurrence of Fusarium and subsequent fumonisin contamination in preharvest and stored maize in Benin, West Africa. International Journal of Food Microbiology 99, 173-183.

FAO/IAEA (2001). Manual on the Application of the HACCP System in Mycotoxin Prevention and Control. Food and Agriculture Organization/ International Atomic Energy Agency, FAO Food and Nutrition Paper 73.

Gajecki, M. (2002). Zearalenone-undesirable substances in feed. Polish Journal of Veterinary Science 5, 117-122.

Galvano, F; Piva, A; Ritieni, A. and Galvano, G. (2001). Dietary strategies to counteract the effects of mycotoxins: a review. Journal of Food Protection 64, 120-131.

Greco, M; Patriarca, A; Terminiello, L; Pinto, V.F. and Pose, G. (2012). Toxigenic Alternaria species form Argentinean blueberries. International Journal of Food Microbiology 154, 187-191.

Hale, G.M. and Wilson, D. M. (1979). Performance of pigs on diets containing heated or unheated corn with or without aflatoxin. Journal of Animal Science 48, 1394-1400.

Harris, B. Jr. (1997). Minimizing mycotoxin problems. Journal of Food Protection 41, 489-492.

Hell, K; Cardwell, K.F; Setamou, M. and Poehling, H.M. (2000a). The influence of storage practices on aflatoxin contamination in maize in four agroecological zones of Benin, West Africa. Journal of Stored Products Research 36, 365-382.

Hell, K; Cardwell, K.F; Setamou, M. and Schulthess, F. (2000b). Influence of insect infestation on aflatoxin contamination of stored maize in four agroecological zones regions in Benin. Afr. Entomol. 6, 169-177.

Hird, S; Stien, C; Kuchenmuller, T. and Green, R. (2009). Meeting report.: second annual meeting of the World Health Organization initiative to estimate the global burden of foodborne diseases. International Journal of Food Microbiology 133, 210-212.

Holbrook,C.C; Guo, B.Z; Wilson, D.M. and Kvien, C. (2004). Effect of drought tolerance on preharvest aflatoxin contamination in peanuts. Proceedings, $4^{\text {th }}$ International Crop Science Congress, Brisbane, Australia, 26 $6^{\text {th }}$ sept- $1^{\text {st }}$ oct. 2004.

IARC (1993). Monograph on the Evaluation of carcinogenic Risk to Humans, International Agency for Research on Cancer, Lyon, Volume 56, pp 257-263.

IPCS (2000). Environmental Health Criteria 219-Fumonisin B1. International Program on Chemical Safety, WHO, Geneva, 150 pp.

Jackson, L.S; Katta, S. K; Fingerhut, D.D; DeVries, J.W. and Bullerman, L.b. (1997). Effects of baking and frying on the fumonisin B1 content of corn-based foods. Journal of Agricultural. Food Chemistry 45, 4800-4805. 
Jard, G; Liboz, T; Mathieu, F; Guyonvarch'h, A. and Lebrihi, A. (2011). Review of mycotoxin reduction in food and feed: from prevention in the field to detoxification by adsorption or transformation. Food Addit. Contamination Part A. Chem. Anal. Exposure Risk Assessment 28, 1590-1609.

JECFA (2001). Ochratoxin A. Joint Food and Agriculture Organization/World Health Organization Expert Committee on Food Additives. http://www.inchem.org/documents/jecfa/jecmono/v47je04.htm accessed on 27-07-2012

Juglal, S; Govinden, R. and Odhav, B. (2002). Spice oil for the control of the co-occurring mycotoxin producing fungi. Journal of Food Production 65, 683-687.

Kabak, B; Dobson, A.D. and Var, I. (2006). Strategies to prevent mycotoxin contamination of food and animal feed. Critical Review of Food Science and Nutrition 46, 593-619.

Kadakal, C. and Nas, S. (2003). Effect of heat treatment and evaporation on patulin and some other properties of apple juice. Journal of the Science of. Food and Agriculture 83, 987-990.

Li, F; Yoshizawa, T; Kawamura, O; Luo, X. and Li, Y. (2001). Aflatoxins and fumonisins in corn from high incidence area of human hepatocellular carcinoma in Guangi, China. Journal of Agricultural and Food Chemistry 49, 4122-4126.

Magan, N. and Aldred, D. (2007). Post-harvest control strategies: minimizing mycotoxicosis in the food chain. International Journal of Food Microbiology 119, 131-139.

Magan, N; Sachis, V. and Aldred, D. (2004). Role of spoilage fungi in seed deterioration. In: Fungal Biotechnology in Agricultural, Food and Environmental Applications, Aurora, D.K. (Ed.), Marcell Dekker, New York, Ch 28, pp 311-323.

McKenzie, K.S; Sarr, A; Mayra, K; Bailey, R.H; Miller, D.R; Rogers, T.D; Norred, W.P; Voss, K.A; Plattner, R.D. and Phillips, T.D. (1997). Chemical degradation of diverse mycotoxins using a novel method of ozone production. Food Chemistry and Toxicology $35,807-820$.

Miller, J.D. (1996). Mycotoxins. In: Proceedings of the Workshop on Mycotoxins in Food in Africa, November, 6-10, 1995, Cardwell, K.F. (Ed.), International Institute of Tropical Agriculture, Cotonou, Benin, pp 18-22.

Munkvold, G.P. and Hellminch, R.L. (2000). Genetically modified, insect resistant maize, implications for management of ear and stalk diseases. Plant Health Program, http://www.planthealthprogress.com /current/reviews/maize/article/htm.

Nehad, E.A; Farag, M.M; Kawther, M.S; Abdel-Samed, A.K.M. and Naguib, K. (2005). Stability of ochratoxin A (OTA) duringprocessing and decaffeination in commercial roasted coffee beans. Food Additives and Contaminants 22, 761-767.

Njapau, H; Muzungaile, E.M. and Changa, R. C. (1998). The effect of village processing techniques on the content of aflatoxins in corn and peanuts in Zambia. Journal of the Science of Food and Agriculture 76., 450-456.

Norton, R.A. (1999). Inhibition of aflatoxin $\mathrm{B}_{1}$ biosynthesis in Aspergillus flavus by anthocyandins and related flavonoids. Journal of Agricultural Chemistry 47, 1230-1240.

Oettle, A.G. (1964). Cancer in Africa, especially in regions South of the Sahara. J. Nat. Cancer Inst. 33, 383-439.

Olojede, F; Engelhardt, G; Wallnofer, P.R. and Adegoke, G.O. (1993). Decrease of growth and aflatoxin production in Aspergillus parasiticus by spices. World Journal of Microbiology and Biotechnology 9, 605-606. 
Park, D.L. (2002). Effect of processing on aflatoxin. Advances in Experimental Medicine and Biology 504, 173-179.

Paster, N; Lisker, N. and Chet, I. (1983). Ochratoxin production by Aspergillus flavus Wilhen grown under controlled atmospheres. Applied and Environmental Microbiology 45, 1136-1139.

Plancinta, C. M; D'Mello, J.P.F. and MacDonald, A.M.C. (1999). A review of worldwide contamination of cereal grains and animal feed with Fusarium mycotoxins. Animal Feed Science and Technology 78, 21-37.

Prudente, A.D. and King, J.M. (2002). Efficacy and safety: evaluation of ozonation to degrade aflatoxin in corn. Journal of Food Science 67, 2866-2872.

Rahmani, A; Jinap, S. and Soleimany, F. (2009). Qualitative and quantitative analysis of mycotoxins. Comprehensive Review in Food Science and Food Safety 8, 202-251.

Reid, L.M; Mather, D.E. and Hamilton, R.I. (1996). Distribution of deoxynivanelenol in Fusarium graminearium-infected maize ears. Phytopathology 86, 110-114.

Robens, J.F. (1990). A perspective on aflatoxins in field crops and animal food products in the United States: A Symposium, United States Department of Agriculture, Agriculture Research Service (USDA-ARS ), Peoria, IL, ARS-83, pp 135.

Robertson, A. (2005). Risk of aflatoxin contamination increases with hot and dry growing conditions. Integrated Crop Management, IC -494 (23), pp185-186. http://www.ipm.iastate.edu/ipm/icm/2005/9-19/aflatoxin.html accessed on 10-04-2012.

Romani, S; Pinnavaia, G.G. and Rosa, M.D. (2003). Influence of roasting levels on ochratoxin A content in coffee. Journal of Agricultural and Food Chemistry 51, 5168-5171.

Rompelberg, C.J; Evertz, S.J; Bruijntes-Rozier, G.C; van den Heuvel, P.D. and Verhagen, H. (1996). Effect of eugenol on the genotoxicity of established mutagens in the liver. Food Chemistry and Toxicology 34, 33-42.

Scheideler, S.E. (1993). Effects of various types of aluminosilicates and aflatoxin B1 on aflatoxin toxicity, chick performance and mineral status. Poultry Science 282-288.

Schell, T.C; Lindemann, M.D; Kornegay, E.T. and Blodgett, D.J. (1993). Effects of feeding aflatoxin-contaminated diets with and without clay to weanling and growing pigs performance, liver function and mineral metabolism. Journal of Animal Science 71, 1209-1218.

Schilder, A; Hancock, J. and Hanson, E. (2006). An integrated approach to disease control in blueberries in Michigan. Acta Horticulturae 715, 481-488.

Scott, P. M. (1984). Effects of processing on mycotoxins. Journal of Food Protection 41, 489-492.

Scott, P.M. (1991). Possibilities of reduction or elimination of mycotoxins present in cereal grains. In: Cereal grain: Mycotoxin, Fungi and Quality in Drying and Storage, Chelkowski, J. (Ed.), Elsievier, New York, pp 529-572.

Scott, G.E. and Zumno, N. (1995). Size of maize sample needed to determine percent of kernel infection by Aspergillus flavus. Plant Diseases 79, 861-864.

Scudamore, K.A; Banks, J. and MacDonald, S.J. (2003). Fate of ochratoxin A in the processing of whole wheat grains during milling and bread production. Food Addit. Contamination 20, 1153-1163.

Seefelder, W; Gossmann, M. and Humpf, H.U. (2002). Analysis of fumonisin B 1 in Fusarium proliferatum-infected asparagus spears and garlic bulbs from Germany by liquid 
chromatography-electrospray ionization mass spectrometry. Journal of Agricultural and Food Chemistry 50, 2778-2781.

Setamou, M; Cardwell, K.F; Schulthess, F. and Hell, K. (1998). Effect of insect damage to maize ears, with special reference to Mussidia nigrivenella on Aspergillus flavus infection and aflatoxin production in maize before harvest in the Republic of Benin. Journal of Econ. Entomology 91, 433-438.

Sewram, V; Nair, J.J; Nieuwouldt, T.W; Leggort, N.I. and Shephard, G.S. (2000). Determination of patulin in apple juice by high-performance liquid chromatographyatmospheric pressure chemical ionization mass spectrometry. Journal of Chromatography A 897: 365-374.

Speijers, G.A. (2004). Patulin, In: Magan, N. and Olsen, M. (Eds), Mycotoxins in Foods, Detection and Control, CRC Press, Boca Raton, FL. pp 339-392.

Thomson, C. and Henke, S.E. (2000). Effects of climate and type of storage container on aflatoxin production in corn and its associated risks to wildlife species. Journal of Wildlife Diseases 36, 172-176.

Tournas, V.H. and Katsoudas, E. (2005). Mould and yeast flora in fresh berries, grapes, and citrus fruits. International Journal of Food Microbiology 105, 11-17.

Turner, P; Sylla, A; Gong, Y; Diallo, M; Sutcliffe, A; Hall, A. and Wild, C. (2005). Reduction of exposure to carcinogenic aflatoxins by postharvest intervention measures in West Africa: a community-based study. Lancet 365, 1950-1959.

Van der Stegen, G.H; Essens, P.J. and van der Lijn, J. (2001). Effects of roasting conditions on reduction of ochratoxin A in coffee. Journal of Agricultural and Food Chemistry 49, 4713-4715.

Visconti, A. (2001). Problems associated with Fusarium mycotoxins in cereals. Bulletin of the Institute for Comprehensive Agricultural Sciences, Kinki University No 9, 39-55.

Voss, K. A; Poling, S.M; Meredith, F.I; Bacon, C.W. and Saunders, D.S. (2001). Fate of fumonisins during the production of fried tortilla chips. Journal of Agricultural and Food Chemistry 49, 3120-3126.

Weidenborner, M. (2001). Encyclopedia of Food Mycotoxins. Springer-Verlag, Berlin, Germany.

WHO (1999). Basic Food Safety for Health Workers. World Health Organization, Geneva, Switzerland.

WHO (2006). Mycotoxins in African foods: Implications to Food Safety and Health. AFRO Food safety Newsletter. World Health Organization Food Safety (FOS)., Issue No. July, 2006. www.afro.who.int./des.

Wood, G.M. (1982). Effects of processing on mycotoxin in maize. Chem. Ind. 972-974.

Yoshida, T; Yamashita, A.and Luo, Y. (1994). Fumonisin occurrence in corn from high and low -risk areas for human esophageal cancer in China. Applied and Environmental Microbiology 60, 1626-1629. 